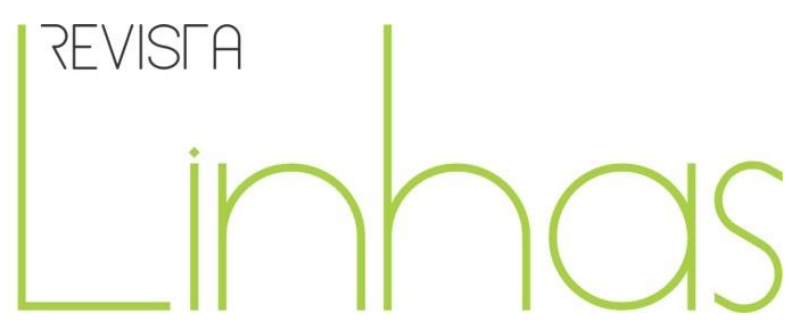

\title{
As fontes para uma história das práticas educativas nas escolas italianas no Rio Grande do Sul (Brasil): da colonização ao período varguista ${ }^{1}$
}

\begin{abstract}
Resumo
Memórias e relatórios didáticos elaborados por professores são fontes úteis para elucidar características das práticas educativas e didáticas e são colocadas entre as formas de escrita profissional que hoje compõem o complexo arcabouço da memória escolar e o tipo de documentos que Viñao Frago classifica como "ego documentos". O estudo de caso que pretendemos apresentar é o referente às memórias e relações produzidas por alguns professores nas escolas italianas no Brasil entre o início da colonização e a queda do fascismo, com um foco específico naqueles produzidos por dois professores italianos que ocuparam o cargo de mestre nas escolas étnicas da quarta colônia Silveira Martins e nas escolas ítalo-brasileiras de Porto Alegre, no estado do Rio Grande do Sul. Antonio Ceretta emigrou para o Rio Grande do Sul em 1880 e, por várias décadas, exerceu a função de professor escrevendo duas importantes memórias; Luigi Ledda chegou à capital do estado gaúcho em 1932 e, durante seus cinco anos de atividades, produziu documentação significativa que auxilia, hoje, a aprofundar as práticas educacionais desenvolvidas dentro de um contexto escolar muito particular. Memórias e relatos produzidos pelos professores são escritos que, do ponto de vista metodológico, devem ser decodificados e interpretados para incluir, também, aquele conjunto de práticas pedagógicas e educativas que estiveram na base das atividades orientadas para a representação da cultura italiana promovida por instituições escolares presentes na área rural e na capital do estado do Rio Grande do Sul.
\end{abstract}

Palavras-chave: Memórias profissionais. Práticas educativas. Escolas étnicas italianas no Brasil. Educação e fascismo no Rio Grande do Sul.

\section{Para citar este artigo:}

BARAUSSE, Alberto. As fontes para uma história das práticas educativas nas escolas italianas no Rio Grande do Sul (Brasil): da colonização ao período varguista. Revista Linhas. Florianópolis, v. 20, n. 44, p. 126-153, set./dez. 2019.

\section{DOI: $10.5965 / 1984723820442019126$}

http://dx.doi.org/10.5965/1984723820442019126

\footnotetext{
${ }^{1}$ Este artigo é uma versão ampliada e revisada daquele apresentado pelo autor em Palma de Maiorca no âmbito da VIII Jornadas científicas de la SEPHE y el I Congresso Nazionale della SIPSE com o titulo Le fonti per una storia delle pratiche educative nelle scuole italiane in Brasile: dalla colonizzazione al fascismo, publicado in GONZÁLEZ, Sara; MEDA, Juri; MOTILLA, Xavier; POMANTE Luigi Aurelio (a cura di). La Práctica educativa. Historia, Memoria y Patrimonio. Salamanca: FahrenHouse, pp. 996-1010.
} 


\title{
Sources for a history of educational practices in Rio Grande do Sul Italian schools (Brazil): from colonization to Vargas period ${ }^{2}$
}

\begin{abstract}
Memories and pedagogical reports elaborated by teachers are useful sources to elucidate characteristics of educational and teaching practices. They are placed among the forms of professional writing that make up the complex framework of school memories nowadays, and the kind of documents Viñao Frago has classified as "Ego-documents". The case study we intend to present refers to the memories and to the lists produced by some teachers in Italian schools in Brazil between the beginning of colonization and the fall of fascism period, with a specific focus on those produced by two Italian teachers who held the position of master teacher in the ethnic schools of the fourth colony named Silveira Martins, and in the Italian-Brazilian schools of Porto Alegre, in Rio Grande do Sul state. Antonio Ceretta, who emigrated to Rio Grande do Sul in 1880, and for many decades worked as a teacher, wrote two important memories. Luigi Ledda arrived in the capital of Rio Grande do Sul state in 1932 and produced, during his five years of activity, a significant documentation that helps, nowadays, to deepen educational practices developed within a very particular school context. From a methodological point of view, memories and reports produced by teachers are the kind of work that must be decoded and interpreted to include the set of pedagogical and teaching practices as well, which were the basis of activities oriented towards the representation of Italian culture promoted by educational institutions in the rural area and in the capital of Rio Grande do Sul state.
\end{abstract}

Keywords: Professional memories. Educational practices. Italian ethnics schools in Brazil. Education and fascism in Rio Grande do Sul.

\footnotetext{
${ }^{2}$ This article is a wider and reviewed version of that presented at Palma de Maiorca, during the VIII Jornadas científicas de la SEPHE y el I Congresso Nazionale della SIPSE, entitled as Le fonti per una storia delle pratiche educative nelle scuole italiane in Brasile: dalla colonizzazione al fascismo, published in Sara González; Juri Meda; Xavier Motilla; Luigi Aurelio Pomante (a cura di) La Práctica educativa. Historia, Memoria y Patrimonio, Salamanca, FahrenHouse, 2018, pp. 996-1010.
} 


\section{Introdução: Novas fontes para novos roteiros de pesquisa sobre a relação}

entre imigração e escola entre os séculos XIX e XX

Um dos fenômenos menos conhecidos na história da educação italiana é o das escolas italianas no exterior. São bastante raras as contribuições que tentaram lançar luz sobre o desenvolvimento das escolas que surgiram desde a unificação nacional e cresceram após a reforma propiciada por Francesco Crispi para imprimir e sustentar a política colonial do novo Estado nacional (FLORIANI, 1974; SALVETTI, 2002). Além disso, o desenvolvimento da educação acompanhou o fenômeno complexo da mobilidade humana da migração. O Brasil constitui um dos espaços geográficos que, mais do que outros, foi receptor das massas de imigração italiana e em cujo território surgiram inúmeras experiências de escolarização, hoje nomeadas étnicas (BARAUSSE, 2016).

Essas são experiências em torno das quais as historiografias italiana e brasileira iniciaram a dedicar-se de maneira mais detalhada, alavancando uma série de fontes cada vez mais complexas (BARAUSSE; LUCHESE, 2017a). Entre estas, um lugar importante é ocupado pelos "ego documentos", ou seja, a tipologia documental produzida pelos professores em diferentes formas, de acordo com a classificação dada por Viñao Frago (2005) e preservada em diferentes locais, dos arquivos públicos aos privados. Entre as tipologias de fontes usadas no âmbito da história da imigração italiana no Brasil, incluemse as memórias. No entanto, estes são "ego documentos" que foram pouco utilizados pela história da educação. É ainda mais surpreendente quando descobrimos que, às vezes, os autores das memórias eram professores.

É o caso das memórias de Giulio Lorenzoni, com curadoria de Franzina (2008), ou de Antonio Ceretta, dois emigrantes vênetos radicados no Rio Grande do Sul. Ambos eram professores. O primeiro, um professor italiano com formação ginasial, como observou o cônsul Perrod (BARAUSSE, 2017a, 2017b), foi nomeado em 1884 como professor das escolas da colônia de Dona Isabel, depois de vencer um concurso. Ocupou esse posto até 1889, quando teve de abandoná-lo em consequência de desentendimentos surgidos dentro da colônia, tensões para as quais não foram estranhos os temores dos componentes mais conservadores que indicavam preocupação com a decisão de Lorenzoni de percorrer a estrada da naturalização brasileira, bem como de animar um clube republicano cuja finalidade era a "desitalianização da colônia" 
(ACTON, 1890, não paginado) e de impedir o desenvolvimento da sociedade local de mútuo socorro. Outro exemplo interessante de memória é o de Antonio Ceretta, que chegou em 1880, aos 12 anos de idade, nas áreas do quarto núcleo de colonização do Estado do Rio Grande do Sul, município de Santa Maria (VENDRAME, 2007) e onde, alguns anos depois, iniciou sua atividade docente, que conduziu por 40 anos na comunidade de São João do Polesine, onde viveu até 1945.

\subsection{As memórias de Antonio Ceretta, professor das escolas étnicas italianas de Vale Vêneto}

A área de colonização criada em 1877, na então região de São Pedro, e chamada de quarta colônia italiana, passou a abrigar uma comunidade significativa de alguns municípios Vênetos (VENDRAME, 2007; ZANINI, 2006) que se instalaram de acordo com as estratégias recorrentes utilizadas pelos imigrantes e bem notadas em uma das duas memórias inéditas deixadas por Antonio Ceretta ${ }^{3}$ : aqueles que partiram primeiro, quando chegaram à terra do destino, escreveram aos parentes deixados em sua terra natal para sugerir que abandonassem seus lugares de origem e os alcançassem, fornecendo-lhes informações sobre as oportunidades que encontraram no exterior.

A cultura escrita e a prática de correspondências favoreceram a manutenção dos vínculos e o intercâmbio entre as duas margens do Atlântico, aumentando as chances de que outras famílias pudessem se aventurar no Brasil (CERETTA, [1941]). Aqui, desde 1884, as autoridades consulares registraram a presença de uma única escola no Vale Vêneto, que reuniu 35 estudantes inicialmente confiados ao pároco, o padre Antonio Sorio, que foi posteriormente substituído pelo professor leigo Luigi Rosso (CORTE, 1884). No espaço de alguns anos, no entanto, especialmente no final dos anos 80 e início dos 90 do século

\footnotetext{
${ }^{3}$ No que se refere a Antonio Ceretta, faz-se referência às duas memórias Historia de Vale Veneto. Desde o ano de 1877 até o año de 1886 Traduzida e remodelata em 1941 (?) da escrita em 1894 [de agora em diante: Memoria Ceretta Vale Vêneto] de agora em diante [CERETTA s.d. mas 1941] e História de São João de Polesine desde o início de sua colonização até o ano de [1936 escrita pelo Professor António Ceretta], s.d. [mas provavelmente de 1936] de agora em diante [CERETTA s.d. mas 1936]. As datas relativas à composição das duas memórias não são exatas. Segundo o arquivista, o caderno que se relaciona com o Vale de Vêneto deve datar de 1894, depois revisado e traduzido para o português, provavelmente em 1941. O segundo, em vez disso, deve ter sido escrito durante a década de 1930, presumivelmente, em 1936. Os Cadernos manuscritos são mantidos no Arquivo Histórico Provincial Nossa Senhora Conquistadora, em Santa Maria, [daqui em diante AHPNSC] dos Padres Palotinos. Agradeço ao arquivista Cleus e ao padre Celsio por disponibilizarem a documentação.
} 
XIX, o contexto relativo à colônia de Silveira Martins, visitado por pelo menos dois cônsules, registrou uma evolução interessante. Se em 1889 o vice-cônsul Acton contava três escolas subsidiadas com 1500 liras para 81 inscritos (ACTON, 1890), dois anos depois, Brichanteau já identificava a presença de sete escolas, algumas das quais novas. Juntamente com a escola sede e as localizadas nos bairros Vale Vêneto e Vale Veronese, de fato, no período de dois anos as autoridades consulares identificaram e subsidiaram outras na Linha Norte, no Núcleo de Soturno, no povoado de Giringonza e no povoado de Arroio Grande (BRICHANTEAU, 1892).

Recentes investigações, através da análise dos relatórios consulares, chamaram atenção sobre a difusão das escolas étnicas italianas nos núcleos coloniais da área da quarta colônia (BARAUSSE; LUCHESE, 2017a).

Neste artigo, focamos sobre a área rural chamada Vale Veronese da colônia onde os cônsules tinham encontrado uma escola mista existente desde 1886, frequentada em 1890 por 28 membros que, dois anos depois, alcançara 40 estudantes e em 1894 já contava com 51, 34 alunos e 17 alunas. Uma escola aberta de janeiro a dezembro, das 8 às 12 horas, durante três dias por semana e instalada "no oratório no belo meio do vale (CERETTA, 1890. Tradução nossa)", como explica o mesmo professor, Antonio Ceretta. Originário da pequena fração de Monticello, pertencente ao município de Lonigo, Vicenza, Antonio Ceretta instalou-se em 1880, aos 16 anos, junto com os demais membros da família, no Vale Vêneto, originalmente chamado de Vale dos Bortoluzzi, pelo grande número de pessoas pertencentes a tal família (RIGHI; BISOGNIN; TORRI, 2001).

O desejo de se juntar aos conterrâneos e explorar as vantagens decorrentes de serem proprietários de terra no sul do Brasil, foi provavelmente uma das razões que levou a família Ceretta a deixar a península italiana. O mesmo arranjo de famílias no Vale do Vêneto, pertencentes aos pequenos municípios de origem, é mais um sinal da existência de redes de comunicação significativas. Provavelmente, Antonio havia deixado seu lugar de origem já possuindo um certo nível de escolarização. Ele sabia ler e escrever, uma habilidade que lhe permitia desempenhar um papel e uma profissão na terra da imigração para garantir sua sobrevivência como professor.

Além disso, o município de origem, o de Lonigo, recebeu uma medalha de ouro por sua contribuição ao desenvolvimento da educação elementar e popular (Presidente 
del Consiglio, 1876) durante a década de 1970. O perfil de Antonio Ceretta é o de um líder professor e mediador dentro da comunidade; um modelo caro à elite governante liberal da segunda metade do século XIX. No vale Veronese, Antonio Ceretta trabalhou imediatamente como professor e catequista para os filhos dos conterrâneos vênetos papel que manteve até o fim da década de 1940 - concordando com os colonos um salário anual de 130 mil réis, o que Ihe permitiu cobrar pouquíssimo dos alunos, pois 120 mil réis estavam cobertos pelo subsídio do governo italiano.

Para Acton, o professor era um agricultor "mas [com habilidade] suficiente para [ministrar] a instrução elementar" e os resultados da escola eram "superiores" aos da sede de Silveira Martins (ACTON, 1890, não paginado). Para o cônsul Brichanteau, o desempenho da escola dirigida pelo "camponês com brincos nas orelhas que faz o que pode, o que é muito pouco" (Tradução nossa) ${ }^{4}$, no entanto, deixou muito a desejar. Durante sua visita, o cônsul chegou a conhecer apenas um aluno capaz de ler sem cantar, entre 30 frequentando a escola mista, que contava com 40 alunos matriculados. Nessa circunstância, ele ficou impressionado com a presença de três crianças capazes de soletrar, mas apenas juntas, em coro, e não individualmente (ACTON, 1890).

O conteúdo das lições era extremamente simples e abordava tópicos de ciência, leitura, escrita, o ábaco na aritmética, ensino religioso "toda sexta-feira" e a explicação das palavras em italiano "quanto minha ciência fraca pode ser capaz" escreveu o professor (L'ANDAMENTO..., s.d.). Ceretta também teve que enfrentar o problema da escassez de livros didáticos para os alunos conforme mencionado no relatório cheio de erros gramaticais enviado ao consulado ${ }^{5}$, a ausência dos silabários teria determinado a baixa frequência dos alunos às aulas, os quais esperavam o material prometido pelo consulado.

Ceretta continuou a exercer a profissão de professor mesmo após a sua mudança para o novo assentamento no núcleo de Soturno, onde se tornou proprietário de um pequeno lote colonial (RIGHI; BISOGNIN; TORRI, 2001), espaço com fronteira entre as montanhas da Serra Geral e o rio Soturno, caracterizado como uma frente de expansão

\footnotetext{
4 "contadino dai pendenti alle orecchie che fa quello che puó che é pochissimo in veritá". Todas as traduções foram feitas por tradução livre.

${ }^{5}$ Ibidem.
} 
familiar na vasta região que incluía a Colônia Silveira Martins. O professor agricultor participou do nascimento da pequena comunidade de São João Polesine. Algumas décadas depois, a narrativa registrada em suas memórias ajudou a reconstruir a identidade e aspectos culturais da nova aglomeração (CERETTA, [1941]).

Esses são elementos que podem ser deduzidos das memórias escritas por ele sobre a história das duas comunidades da região colonial com as quais manteve um vínculo durante sua vida, depois de ter cumprido a necessidade de assegurar formas de vida e piedade religiosa. Com a construção da capela, intitulada São João Batista, Ceretta foi movido principalmente pela preocupação de garantir a educação religiosa aos filhos dos colonos a partir do ensino do catecismo. É uma atitude comum àqueles fiéis ou àqueles professores de filiação católica que, durante a segunda metade do século XIX, apesar de posições ligadas à cultura católica da intransigência, se dedicaram a ensinar as ferramentas básicas para a alfabetização como caminho agora indispensável para ingresso nessa modernidade ideologicamente contrastada - através das encíclicas e dos documentos oficiais.

$\mathrm{Na}$ prática cotidiana, esta serviria como instrumento justamente para não alimentar o distanciamento das massas populares, camponeses ou trabalhadores que estavam prestes a passar para as fileiras do socialismo ou organizações sindicais. Nesse cenário, Ceretta compreendeu a necessidade fundamental de administrar o ensino básico de leitura e escrita, mesmo diante da ausência de iniciativas das instituições do novo Estado brasileiro republicano:

Naqueles tempos o governo não se preocupava muito com as escolas e tampouco o município; e nos de muita boa vontade deixaríamos escrever a outros estas páginas, para nòs nada gostosas. Mas não havendo possibilidade de substituto procuraremos faze-lo o mais modestamente possível. Naqueles tempos os nossos governantes não se sentiam queimar o coração desta chama de nacionalismo atual. Nada disto o Brasil de então, era o Brasil da política e dos politiqueiros. Tempos das revoluções partidárias, ode os pretendentes á panela se diziam continuamente: Desce tu, que sobo (sic) eu, e assim, gastavam as suas energias junto com o dinheiro público, sem entrilhar o Pais para um rumo de amor pátrio e de um justo nacionalismo. [...] Antes com as amplas libertades existentes, cada grupo colonial podia abrir escolas e ensinar na própria língua da origem [...]. (CERETTA, [1936], p. 34-35) 
Nos anos em que dominou o espírito do nacionalismo brasileiro de Vargas, Ceretta relatou as fases pioneiras das escolas étnicas, explicando a existência das condições que permitiram a muitos iniciar as experiências de escolarização étnica nas novas colônias, não apenas as da matriz italiana, mas também alemã, quadro favorecido pelo absenteísmo do governo imperial e republicano brasileiro. Condições, além disso, como eram bem conhecidas por Ceretta, que geralmente envolviam muitas escolas italianas espalhadas pelo exterior. Ceretta também lembra o propósito de preservar a língua nacional e a identidade das escolas:

\begin{abstract}
Antes com as amplas liberdades existentes, cada grupo colonial podia abrir escolas e ensinar na própria língua de origem. Não era, pois, de admirar que cada nacionalidade, procurasse cultivar e amar o seu idioma porque aprendido da própria mãe e ouvido continuamente falar na própria família e entre suas gentes com as quais se achava continuamente em contato. Estando as causas nesta altura, cada grupo que se sentia impulsionado pelo dever, de abrir uma escola, escolhia o mestre entre os seus e as lições era dada (sic) no idioma a que o grupo pertencia, se italiano, ensinavam o italiano, se alemães, alemão etc. É preciso notar que cada nação da Europa, que tinha seus filhos espalhados pelo mundo: pois não se deve pensar que isso se desse só com o Brasil, não, por qualquer parte do mundo, uma nação tivesse de seus súbditos, acompanhava-os com a instrução afim conservando (sic) o próprio idioma, conservassem também o amor a sua pátria de origem. Assim, por meio dos cônsules e vice-cônsules, aconselhavam e promoviam escolas entre as colônias, auxiliando-as com dar-lhe os materiais necessários, como livros, cadernos, enfim tudo o necessário, até tinta e giz e mapas. (CERETTA, [1936], p. 35-36)
\end{abstract}

Foi graças ao papel particular exercido pelo professor que, imediatamente após a constituição da capela, surgiu a primeira escola do núcleo colonial para responder à demanda de muitos pais para educar seus filhos. Em suas memórias, Ceretta relata que a decisão de seguir o caminho do ensino também na nova comunidade foi tomada após a proposta apresentada por outro dos primeiros professores e líderes da comunidade de Vale Vêneto, Luigi Rosso, que foi particularmente cuidadoso para promover iniciativas destinadas a garantirem a educação dele e dos outros filhos da colônia:

Nos tempos em que o Polesine foi colonizado, estava-se nesses sistemas de causas. Todos os paes (sic) que tinha filhos em idade, e compreendiam a necessidade da instrução, lastimavam, não houvesse 
(sic) uma escola para onde mandar seus filhos aprender. Antes de tudo não havia entre os colonos pessoal preparado para tal oficio, e também bem raro cá e lá se dava que uma pessoa se sentisse inclinada a exercer tal oficio, pois, pelos mais, dava mais gastios (sic), do que lucro. Em São João do Polesine, o que mais se ocupava para resolver o problema da escola, era Luiz Rosso, pois era ele o que mais entendia o valor da instrução, e ele fez apontamento sobre o catecista. Este também andava preocupado com o mesmo problema, pois tendo ele mesmo filhos e filhas, não queria que eles crescesem (sic) sem instrução. Mas tinha resolvido, ser ele mesmo o mestre de seus filhos: e, graças a Deus, o foi de todos. No ano de 1897, tendo chegado de São Paulo uma irmã da mulher do catecista, a qual tinha duas filhas e um filho, começou ocuparse uma hora por dia, ao (sic) depois de meio dia, sacrificando o seu descanso, e ensinar ler e escrever a duas de suas filhas que estavam em idade, e aos três sobrinhos. Um dia Luiz Rosso lhe disse: Sabes que ha tempo estou pensando em tantas gurizadas que cresce no nosso Polesine, e sem instrução. Queres tu ser mestre-escola e eu te ajudarei o mais possível arrumar as cousas. O catecista, que embora sentisse estimulo para o oficio de ensinante, todavia achava a cousa dificoltosa (sic!), pois ele morava a mil quinhentos metros de distancia da Capela e com uma estrada nada comoda. (CERETTA, [1936], p. 36-37)

Ceretta lembra que as famílias que tinham filhos para mandar para a escola "eram poucas e pobres e muito pouco podiam pagar", mas a insistência do amigo era de induzir o professor a aceitar: "E feito por suas próprias mãos e com uma madeira meia dúzia de toscos bancos" no início de outubro de 1898, começou a dar aulas na capela que ainda não havia sido abençoada "e apenas uma dúzia de estudantes que pagariam mil réis por mês de cada um" apareciam registrados: um contexto considerado "para desaminar, e só um grande espírito de sacrifício podia aconselhar à perseverança" (CERETTA, [1936], p. 39). As dificuldades foram acentuadas após a bênção da capela - ocorrida em janeiro -, pois o pároco não considerou apropriado autorizar a continuidade das atividades e, por isso, foram suspensas para serem retomadas apenas em julho, depois de concluídas as obras de construção da escola de madeira:

Mas logo se deram início a fazerem-se (sic) uma casa em madeira pela escola, e em primeiro de Julho do mesmo ano de 1899 , começou-se nela lecionar. Não verdadeiramente uma casa, mas sim uma miraveis (sic) cabana, coberta de taboinha e fechada de taboas, tendo 4 metros de largo com 6 metros de cumprido e com a altura de apenas dois metros e vinte centimitros. Esta miseravel cabana, não só servia de escola, mas por uns dez anos, pelos menos, serviu tambem de dormitorio aos Padres nas visitas que faziam do Polesine. (CERETTA, [1936],p. 39) 
Particularmente interessantes são as considerações do mestre vêneto sobre as práticas de ensino utilizadas:

O ensino era dado em italiano, pois ninguém pensava, como já temos notado, em mandar seus filhos aprender português, e o mesmo mestreescola, naquele tempo, mal o sabia ler. Demais, a gente era tão pobre naquele tempo, que nem poderia sustentar as despesas do necessario para o material necessário para a escola. Por conseguinte, o professor fez pedido ao vice-cônsul, que era naquele tempo o Vigário de Silveira Martins, se dignasse auxiliar esta nova escola, proporcionando-lhe $o$ material necessario. E o vice-cônsul aquiesceu muito complacente, pois, mesmo naqueles dias, tinha ele recebido do cônsul de Porto Alegre, uma grande remessa de material para distribuílo às escolas. E assim foi a escola de Polesine, alistada entre a escola italiana subvencionada, o que Ihe valeu tambem, para realçar o seu moral, porque diziam: Aí os livros, cadernos e tudo o necessário são dados gratuitamente, por isto convém aproveitar. (CERETTA, [1936], p. 40)

As memórias dos emigrantes representam uma fonte sobre a qual se manifestou um renovado interesse por parte dos historiadores, tanto no lado italiano como no brasileiro (DE RUGGIERO, 2018; VENDRAME, 2007, 2018; ZANINI, 2006), e em torno do qual algumas precauções metodológicas devem ser mantidas. É necessário problematizar a fonte, compreender o momento da produção, a posição e o lugar social ocupado pelo escritor. Especificar o contexto em que foi desenvolvido nos permite entender como o passado foi retrabalhado. Alguns fatos são lembrados e outros não.

Escrever e contar as experiências vividas nas áreas de colonização ou imigração era um exercício cultivado, uma aspiração para vários membros das novas colônias. Muitos deles, além disso, não estavam em posição de escrever porque lhes faltavam as habilidades de escretia ou o tempo para fazê-lo. Devemos também ter em mente que as memórias nas quais buscamos os elementos de interesse foram escritas para contar e transmitir um "épico", uma "epopeia". Nós poderíamos falar nesse sentido de um verdadeiro e próprio gênero. Como tal, as memórias acabam reforçando uma certa identidade e narrativa. E os autores das memórias sempre fazem uma seleção dos fatos que pretendem contar, omitindo outros. As experiências mencionadas frequentemente encontram suas limitações no que a comunidade deseja lembrar. Mas nas memórias, embora parciais, os imigrantes deixaram vestígios dos problemas e tensões experimentados nas comunidades coloniais nas últimas décadas do século XIX e início do 
século XX (FRANZINA 2014; VENDRAME 2018). Os diários, memórias e escritos de imigrantes são materiais muito ricos para analisar de perto não apenas os mecanismos de transferência, acomodação e organização das famílias nos núcleos coloniais. Mas partindo de suas perspectivas individuais e das diferentes expectativas e itinerários empreendidos dentro de contextos específicos de colonização, eles também podem ajudar a entender as dinâmicas e os problemas que mais frequentemente acompanhavam os processos de educação e a profissão de professor.

Esses documentos, analisados através de considerações críticas apropriadas, podem abrir outros olhares sobre as primeiras formas de escolarização e aquelas que caracterizaram o período da segunda e da terceira colonização e que mereceriam mais investigações. Mas, entre os "ego documentos" que pouco foram levados em consideração, há aqueles preservados dentro das "fontes consulares" (BARAUSSE; LUCHESE, 2019) que se referem ao desenvolvimento, no Brasil, das escolas italianas subsidiadas. Nesta documentação existem traços significativos de "ego-documentos" produzidos por professores durante o período seguinte, aquele compreendido entre as décadas que viram o fascismo crescer e consolidar-se na Itália, e no Brasil, entre os anos de 1930 e 1937, com a crise da República Velha e o nascimento do Estado Novo, liderado por Getúlio Vargas.

\subsection{Os escritos profissionais de um professor em um contexto urbano de imigração: Luigi Ledda e o desenvolvimento das escolas étnicas italianas na área urbana de Porto Alegre}

No segundo estudo de caso analisado, é possível revelar o valor heurístico dos escritos profissionais de um dos professores que acompanharam o processo de reorganização das escolas no contexto urbano de Porto Alegre. Precisamente na capital gaúcha, como revelaram pesquisas recentes, as autoridades consulares favoreceram e possibilitaram um processo de reorganização das escolas presentes e vinculadas às associações de mútuo socorro (BARAUSSE, LUCHESE, 2017b; LE SCUOLE..., 1936; RECH, 2015). Dotadas de diferentes características, tanto do ponto de vista curricular quanto em relação à proximidade com o consulado, foram reconduzidas a uma reorganização sob a proteção direta do consulado, coordenadas através de uma única direção didática (II 23 MARZO..., 1933). 
Muito sinteticamente, o projeto de reorganização, acompanhado por uma incisiva campanha da imprensa, consistiu nas seguintes passagens: a institucionalização de uma direção didática para centralizar e unificar a coordenação de atividades sob uma estrutura única; a estruturação de um currículo comum que exigia o ensino de italiano e português; a consolidação de um calendário para assegurar o exercício efetivo do ano letivo e um horário escolar com a distribuição da carga horária semanal; o uso uniforme de livros didáticos; a adaptação do espaço físico em termos de salas de aula; o aumento do número de alunos inscritos e o acompanhamento para garantir a frequência escolar; o serviço regular de inspeção e orientação pedagógica para professores; o fornecimento às escolas do material didático necessário e apropriado ao trabalho pedagógico; a organização de um calendário de comemorações e festividades conjuntas junto às autoridades brasileiras (LA NUOVA..., 1933; LE NOSTRE..., 1933).

As várias ações também foram apoiadas por outros tipos de intervenções de natureza extracurricular, tais como: tratamento médico, merenda escolar, atividades de acampamento de verão, o envolvimento específico de professores no ensino de música, canto, coral e educação física. As escolas assim reorganizadas assumiram, agora, o nome de escolas ítalo-brasileiras (BARAUSSE, LUCHESE, 2017b). O processo foi realizado através do envolvimento das autoridades gaúchas, que garantiram de forma gratuita os professores e as professoras para o ensino de português nessas escolas (RECH, 2015).

O processo de reorganização e de gestão não foi curto e atravessou a direção de três cônsules, todos muito mais alinhados com as orientações do regime fascista que os cônsules anteriores: Mario Carli, Guglielmo Barbarisi e Santovincenzo Magno (BERTONHA, 2001). O impulso para o desenvolvimento das escolas foi inscrito no quadro de uma estratégia mais orgânica que, a partir da primeira metade da década de 1930, após a viagem de Pietro Parini ao Brasil em 1931, viu os cônsules italianos de Porto Alegre avançarem para o estabelecimento de uma nova associação de caráter federativo, que reuniu as oito sociedades italianas existentes na capital para assegurar, junto com um controle mais direto, a obtenção de maiores recursos financeiros (CARLI, 1933a) e para o envolvimento de todas as organizações na proposta fascista, também mediante a inauguração de novos jornais para campanhas de imprensa incisivas, o uso de rádio, a inauguração e a promoção de novos monumentos e festividades. Estratégias para a 
construção de um sentimento de pertença à "Grande Itália", ao italianismo e, portanto, ao fascismo (II REGIO CONSOLE..., 1937).

\subsection{De Tunisi a Porto Alegre}

É nesse cenário que se coloca a atividade profissional de Luigi Ledda, que chegou ao Brasil aos 29 anos. Na verdade, o jovem professor nasceu em Nuoro, na Sardenha, em 12 de julho de 1903. Depois de obter seu diploma de professor primário na escola normal de Nuoro, matriculou-se, em 1920-21, no curso de especialização estabelecido na Faculdade de letras e filosofia de Roma, mas, provavelmente, não conseguiu seguir as lições. Naquele mesmo ano letivo, na verdade, fora nomeado professor temporário na escola de um povoado de Berruiles, na província de Nuoro e, no ano seguinte, na escola do município de Ussana, na província de Cagliari. Em 1923, venceu o concurso como professor titular do município de Terranova Pausania em Sassari. Nesse mesmo ano, começou o serviço militar, ganhando, em 1924 o título de "allievo ufficiale"6.

Entre 1924 e 1927, ensinou nas escolas do município de Terranova Pausania e, nos dois anos seguintes, no curso suplementar e na escola de iniciação ao trabalho. Depois de vencer o concurso anunciado em 1929, com uma pontuação 8 de 10, ele foi enviado para Tunísia, onde chegou no dia $1^{\circ}$ de setembro de 1929, permanecendo lá por três anos. A direção geral das escolas e dos italianos no exterior, na verdade, destinou-o às Américas e, em 18 de julho de 1932, ele partiu de Gênova para o Brasil. Precisamente após a reorganização desejada pelo cônsul de Porto Alegre, a partir de $1^{\circ}$ de janeiro de 1934, Ledda assumiu também a função de administrar a escola italiana de Porto Alegre, cargo que ocupou até deixar a capital gaúcha em 1938. Depois da experiência no sul do Brasil, Ledda teria passado no Paraguai de onde, no entanto, por razões de natureza disciplinar, foi expulso em 1939 (TONI, 1939a, 1939b). Retornando a Roma, não sem controvérsia, Ledda foi então enviado para Bremen, na Alemanha, onde permaneceu até setembro de 1941, quando, após um pedido explícito para que renunciasse como professor primário em escolas do exterior, retornou às escolas nacionais na diretoria da Frosinone.

\footnotetext{
${ }^{6}$ Qualificação que recebem os militares durante o treinamento e os estudos para obter a posição de comando dentro de uma força militar.
} 
Ledda chegou a Porto Alegre com forte crédito. As avaliações dos inspetores atribuíram ao jovem professor uma pontuação muito alta, aquela correspondente a 10. Assim, começou a lecionar em uma turma de 37 alunos, todos, com exceção de um, de nacionalidade italiana. Sua cultura geral era considerada "notável" e suas habilidades didáticas "notáveis": Ledda era capaz de manter a disciplina observando "os cânones e ditames da ética fascista" (CARLI 1933b). Tendo chegado recentemente ao Estado do Rio Grande do Sul, ele não tinha um conhecimento particular do país, que, no entanto, foi aprofundado ao longo dos anos. Desde o início, o professor mostrou que queria contribuir para melhorar a situação das escolas de Porto Alegre, através da participação no nascimento de duas novas escolas (CARLI, 1933b).

Os "escritos profissionais" do professor nos dão uma sensação de uma evolução particularmente significativa das escolas italianas em Porto Alegre. Os primeiros relatórios, em particular os produzidos no final de 1932, após apenas seis meses da sua chegada, lembram a condição de forte precariedade organizacional e disciplinar das escolas urbanas da capital sul-rio-grandense as quais "não gozam, infelizmente, de boa fama" (LEDDA 1932a, p. 2. Tradução nossa ${ }^{7}$ ). O professor expressou fortes críticas ao modelo de ensino e à estrutura adotados nas duas escolas fomentadas pelas sociedades de mútuo socorro, a Umberto I e a Escola Principessa Elena di Montenegro.

Seus primeiros relatos apontam também as limitações quanto ao material escolar; os limites do espaço escolar pouco “[...] adequado para formar as almas", ; ausência de "programas didáticos detalhados e que os inspetores didáticos, como normalmente são chamados, são incompetentes, quando não são analfabetos" (LEDDA, 1932a, p. 1. Tradução nossa ${ }^{9}$ ). As observações de Ledda lembram a condição de forte precariedade organizacional e disciplinar das escolas urbanas da capital da cidade e, talvez os tons se acentuassem pela necessidade de marcar o trabalho feito com o propósito de reorganização, mas Ledda não desiste de usar uma representação bastante negativa da situação:

\footnotetext{
7 “non godono, purtroppo, di buona fama".

8 “adeguato per formare anime".

9 "programmi didattici dettagliati e che gli ispettori didattici come normalmente sono chiamati, sono incompetenti, quando non sono analfabeti”.
} 
Para ter uma ideia clara sobre as condições reais em que essas duas escolas estão, antes da minha contratação em serviço [...] é necessário saber que os alunos a mim designados, são um verdadeiro espelho da situação escolar em geral, eram indisciplinados, não observavam o horário, esvaziavam a escola durante a estação chuvosa, não compareciam regularmente nos outros períodos, não justificando as ausências. Nos cadernos e nos livros, mantinham grande desordem, um mundo variado de desenhos e fantoches, uma alegre e avassaladora explosão de vida que urgentemente pedia seu lugar na atividade legal da escola. (LEDDA, 1932b, p. 3. Tradução nossa ${ }^{10}$ )

Um quadro, portanto, bem diferente daquele que apresentaria nos anos seguintes, quando, com entusiasmo, enfatizou: "Pela primeira vez, enfim, vi em nossas escolas alunos de seis anos, autoconfiantes, bonitos, muito limpos" (LEDDA, 1935b, não paginado. Tradução nossa ${ }^{11}$ ) ou quando a autoridade consular relembrou o crescimento quantitativo significativo de alunos matriculados, de três, que se tornaram cinco, e envolveram oito professores (três dos quais eram permanentes e cinco temporários) sublinhando como: “As poucas dezenas de estudantes de 1932 agora são multiplicados, disciplinaram-se, limpos, todos usam aventais, frequentam nossas escolas com entusiasmo e proveito. Eles agora alcançam a figura respeitável de 367 estudantes" (LEDDA, 1936a, não paginado. Tradução nossa ${ }^{12}$ ). Ou quando, novamente, com a mesma satisfação, ele anunciou o envolvimento da comunidade italiana para a conclusão do mobiliário das escolas (LEDDA, 1937a).

O novo professor indicava a necessidade de um alinhamento ao modelo da escola fascista que queria estabelecer e fazer com que os alunos "[...] amem a Itália fascista com a qual serão levados a estabelecer relações intelectuais e econômicas" (LEDDA, 1932a, p. 2). Nessa perspectiva, Ledda esperava uma diferente dotação de material e artefatos auxiliares escolares “[...] disponibilizando-o antes do período das inscrições escolares. [...]

\footnotetext{
10 "Per avere un'idea chiara sulle condizioni reali in cui si trovano queste due scuole, prima della mia assunzione in servizio [...] è necessario sapere che gli alunni a me assegnati, specchio fedele della situazione scolastica in generale, erano indisciplinati, non osservavano l'orario, dissertavano la scuola durante la stagione piovosa, non la frequentavano regolarmente negli altri periodi non curandosi di giustificare le assenze. Nei quaderni e nei libri, tenuti in gran disordine, un mondo vario di disegni e di pupazzi, esplosione gioconda e prepotente di vita che chiedeva d'urgenza il suo posto nell'attività legale della scuola".

11 “Per la prima volta, insomma, ho visto, nelle nostre scuole, alunni di sei anni spigliati, graziosi, pulitissimi”.

12 "Le poche decine di alunni del 1932 si sono ora moltiplicate, e disciplinati, puliti, tutti in grembiule, frequentano le nostre scuole con entusiasmo e profitto. Raggiungono ora la rispettabile cifra di 367 alunni".
} 
As escolas devem ter os decorosos quadros de Sua Majestade o Rei, de Sua Majestade, a Rainha, e do Duce" (LEDDA, 1932a, p. 3-4).

A autoridade consular apreciou o ensinamento do professor que exercia "com absoluta consciência de sua missão, em conformidade com as diretrizes do governo nacional, [...] demonstrando ter assimilado perfeitamente os princípios inspirados pelo ensino da didática fascista". Além de participar "com entusiasmo" nas manifestações patrióticas, ele parecia expressar uma tradição de estudo "assídua" especialmente para as disciplinas pedagógicas, históricas e filosóficas em geral, e após apenas nove meses foi proposto, pela nomeação formal, como diretor didático (CARLI, 1933b, p. 3). As apreciações e a estima desfrutadas pelo professor também são notadas em algumas observações específicas escritas por Carli:

\begin{abstract}
Penso que o mestre Luigi Ledda, não só merece a nomeação imediata como Diretor Didático, mas que isso deve ser complementado por uma qualificação profissional ou cavalheiresca que lhe dá o prestígio que ele tem direito a um Chefe de Instituto e Diretor de escolas oficialmente reconhecidas. Aqui o título mínimo dado a um "maestro" é o de "Professor", e como não sei e não desejo me afastar do uso italiano, continuo a chamar Ledda di "Maestro", um título que ele altamente honra mas que o diminui aos olhos dos brasileiros. Acredito que, se não puder ser promovido do lado profissional, a melhor solução seria decorálo com a Cruz de Cavaleiro da Coroa da Itália e uma distinção especial da escola, se existir. Isto diz ao Ministério Superior toda a estima e consideração que Mestre Ledda desfruta deste cargo, tanto dos estudantes como de suas respectivas famílias, por suas atividades multiformes, por suas iniciativas sempre novas, pela atitude instintiva ensino e formação fascista das crianças italianas no exterior. (CARLI, 1933b, não paginado).
\end{abstract}

\title{
1.4 A italianidade como valor pedagógico e prática didática
}

Os escritos profissionais também nos orientam melhor sobre as práticas e os conteúdos de ensino exercidos pelo professor. Das fontes, de fato, surge a centralidade atribuída por Ledda ao ensino de línguas. O exercício profissional é impulsionado pela "firme convicção nos professores de que nossas escolas estrangeiras colocam o ensino da língua materna como a primeira razão da sua existência" (LEDDA, 1937b, não paginado). Na perspectiva do professor e diretor didático das escolas étnicas de Porto 
Alegre, de acordo com os novos programas elaborados pela direção geral das escolas e dos italianos no exterior, do ministério das relações exteriores através de Piero Parini, a dimensão do italiano constitui um valor pedagógico e uma prática didática ${ }^{13}$.

Os programas de 18 de outubro de 1930 especificavam que "[... ] o ensinamento fundamental deve ser sempre a língua italiana, como a que melhor permite a formação de uma consciência nacional sólida, a valorização de nossos ideais de pátria e civilização, nossa expansão cultural" (PARINI, 1934, p. 104). E, portanto, nessa linha, o diretor compromete-se a introduzir novas abordagens, como a redução de exercícios escritos em favor do oral para aumentar a conversação, um trabalho para combater a presença de vários problemas ditados por "condições ambientais difíceis" pela falta de cooperação entre as famílias e o hábito de falar em dialeto ou em português (LEDDA, 1937b, não paginado). Nos critérios de Ledda, para verificar e ilustrar o avanço na disciplina linguística, o uso do italiano no cotidiano se coloca sempre:

Nos passeios, no pátio, no campo esportivo, a língua falada começa a ser normalmente a nossa. Em sala, ninguém se atreve a exprimir-se em português. [...] É na boca de todos, na Comunidade, que muitos pais, que abandonaram o uso da nossa língua em casa, voltaram a fazê-lo graças aos seus filhos [...]

Depois de três anos de trabalho, o ambiente escolar das escolas locais tornou-se primorosamente italiano: os novos estudantes agora seguem os antigos que recuperaram a Itália, apesar de amarem e sentirem sentimentos nobres pelas terras onde nasceram. O ambiente é um fator decisivo para a formação espiritual da criança [...] Em todas as escolas, o primeiro grupo de alunos já foi criado para falar italiano sempre e em toda a parte durante a permanência na escola; os outros, os recémchegados devem se instalar e fazê-lo sem grandes dificuldades. No primeiro e no segundo ano, o respeito humano foi o obstáculo mais sério. Agora, os olhos a princípio distraídos, tímidos ou mesmo hostis, em um curto espaço de tempo, ilumina-se de amor pelo professor e orgulho pela pátria distante, enquanto antes parecia impossível. (LEDDA, 1935b, não paginado. Tradução nossa ${ }^{14}$ )

13 “[...] l'insegnamento fondamentale dev'essere sempre la lingua italiana, come quello che meglio permette la formazione di una salda coscienza nazionale, la valorizzazione dei nostri ideali di Patria e di civiltà, la nostra espansione culturale" (PROGRAMMI, 18 ottobre 1930, p. 104).

14 "Dopo un triennio di lavoro l'ambiente scolastico delle scuole locali è divenuto squisitamente italiano: $\mathrm{i}$ nuovi alunni seguono ormai gli anziani che sono riconquistati all'Italia, pur amando e sentendo essi nobili sentimenti per le terre che li vede nascere. L'ambiente è fattore decisivo per la formazione spirituale del fanciullo[...] In ogni scuola ormai si è già costituito il primo gruppo di alunni che parla l'italiano sempre e ovunque durante la permanenza a scuola; gli altri, i nuovi arrivati devono ambientarsi e lo fanno senza gravi difficoltà. Il primo e il secondo anno il rispetto umano era il più grave ostacolo. Ora, occhi in principio distratti, timidi, od addirittura ostili, in breve giro di tempo si illuninano di amore per il maestro e di orgoglio 
Os relatórios de Ledda destacam o trabalho organizacional e a diversidade de abordagens didáticas destinadas a introduzir cada vez mais uma didática ativa que parecia ser completamente desconhecida para os professores locais temporários. Nos relatórios do professor - que em breve será nomeado diretor - a cultura magistral é refletida. No início, o professor é forçado a se deslocar a um ambiente escolar pouco homogêneo, no qual observa que entre "um estudante e outro há enormes diferenças"15" detectáveis pelos cadernos escolares cheios de "exercícios secos e mortais de análise gramatical, enquanto os alunos não sabiam ler, falar"16; e com "exercícios asfixiantes de cópias ${ }^{17}$ ", enquanto em contraste "os alunos da quarta série não conheciam as ligações entre duas letras ${ }^{18 \% "}$. Ou de operações "com números fabulosos, e o primeiro da escola não podia ler um número dentro dos limites do programa"19 (LEDDA, 1932b, p. 3. Tradução nossa).

Partindo desse contexto, o professor da Sardenha tenta introduzir as inovações que a cultura magistral idealista de Lombardo Radice procurou espalhar entre os professores. Nesse sentido, os relatórios do professor mostram, por exemplo, a introdução, nas primeiras classes elementares, de novas ferramentas para promover um aprendizado mais rápido e eficaz da leitura e da escrita, como o alfabeto móvel sobre o qual, desde o final da década de 1920, foi apontado o interesse de alguns professores atentos à inovação metodológica. Da mesma forma, foi dada atenção específica ao ensino de cálculo oral para permitir uma aprendizagem mais consciente e concreta de números e menos abstrata. Na mesma direção de uma modernização das técnicas de ensino, foi o programa de atuação, educação física, desenhando através da promoção daquelas iniciativas destinadas a nutrir e apoiar o modelo educacional fascista.

Entre esses, por exemplo, os ensaios de ginástica organizados nos dias 24 e 28 de maio, o canto, a correspondência interescolar, as premiações mensais para os alunos que fizeram os melhores desenhos ou que mantiveram os cadernos em ordem, os prêmios

\footnotetext{
per la Patria lontana, mentre prima pareva impossibile”.

15 "un alunno e l'altro differenze enormi".

16 “esercizi aridi e micidiali di analisi grammaticale mentre gli alunni non sapevano leggere, parlare”.

17 “esercizi asfissianti di copiatura".

18 "gli alunni di quarta non conoscevano i nessi fra due lettere".

19 “con numeri favolosi, ed il primo della scuola non sapeva leggere un numero entro i limiti del programmi”.
} 
especiais para as competições de história e geografia ou de desenho, a participação em competições, como a promovida pelo jornal infantil fascista "Il Tamburino" no exterior, pela qual, em 1935 ele obteve o terceiro lugar no ranking mundial (LEDDA, 1935b; LEDDA 1936, p. s.n.). A promoção contínua de jogos e a organização de acampamentos de verão “Benito Mussolini” (LEDDA, 1937b, não paginado).

\section{5 “Apostolado civil e patriótico além das fronteiras do Reino": as iniciativas para a arregimentação fascista}

O diretor didático da Sardenha reflete esse modelo de professor, caro à retórica da hierarquia fascista, que teve de desempenhar o papel de mediação entre a pátria e os italianos no exterior. Sobre os professores e diretores das escolas italianas no exterior, são exercidas as expectativas das classes dominantes fascistas, para as quais eles representam a "sentinela avançada da pátria distante" 20 . Sua tarefa era "manter viva a memória e o culto" 21 em contextos marcados por problemas específicos que não escaparam ao legislador, como as diferenças de língua, religião, a confusão causada pela presença de dialetos originais nas comunidades italianas, a ausência de tradições locais a partir das quais se desenha "como viver as fontes da cultura regional”22, a necessidade de conviver com o ensino de outras línguas. Pede que se desenvolva uma prática profissional e uma forma de estar na sociedade de acolhimento adequada a estes propósitos (NUOVI ORARI E PROGRAMMI, 1 ottobre 1924, p. 86).

Essas tarefas foram ainda melhor especificadas por Parini em 1930. Aqui, então, os traços dos professores não serão somente aqueles “do apostolado civil e patriótico para além das fronteiras do Reino" 23 , mas de professores animados de "zelo patriótico vivo e iluminado pela luz que emana da doutrina e do estilo fascista" (PARINI, 1934, p. 107. Tradução nossa ${ }^{24}$ ) que estarão muito próximos dos do propagandista a fim de que a escola possa ser um "meio muito poderoso de manter a coletividade da América do Sul perto dos ideais italianos"25 (PARINI, 1935, não paginado, tradução nossa). E os relatos do

\footnotetext{
20 "sentinella avanzata della Patria lontana".

21 "mantener vivi la memoria e il culto".

22 "come vivere le fonti della cultura regionale".

23 “dell'apostolato civile e patriottico oltre i confini del Regno".

24 "vivo zelo patriottico e illuminati dalla luce che emana dalla dottrina e dallo stile fascista".

25 “mezzo potentissimo per tener avvinto alle idealità italiane le collettività del Sud America”.
} 
diretor didático têm um estilo participativo, percebe-se o envolvimento, reflexo de uma maneira de conceber o próprio trabalho, a própria profissão como uma verdadeira militante, até que se leve a um compromisso ideológico aberto. "Para educar os alunos para o culto da Itália e do Duce" (LEDDA, 1935b, não paginado, tradução nossa ${ }^{26}$ ) aos professores, como Ledda, é solicitado um compromisso assíduo e global, um compromisso não só contido em horas de trabalho, mas dirigido a toda a comunidade italiana com um dinamismo inédito e cheio de politização que, no entanto, deve ser exercido com grande prudência para não perturbar as autoridades brasileiras.

Os relatórios revelam, assim, o compromisso de Ledda em organizar e arregimentar melhor os filhos pequenos dos imigrantes. Desde abril de 1933, ele trabalhou para a criação de organizações juvenis fascistas que deveriam ter substituído o patrocínio de acordo com as disposições da administração geral. De 1934 a 1937, ele foi o líder da O.G.I.E., alcançando também a qualificação de “ótimo", tanto que, em 1937 e 1938, assumiu a qualificação de vice-comandante da G.I.L.E. Mas as práticas do fascismo também passaram pelos ritos e cerimônias previstos pelo novo curso a partir do festival da bandeira ou pelo encerramento das atividades no final do ano. Identificou-se uma rotina que se observará até 1938: no sábado, havia a saudação à bandeira durante a qual os melhores alunos de cada série eram chamados a recitar canções e hinos. Quanto a esse aspecto vivenciado pelos discentes, Luigi Ledda frisava que “[...] dessa forma esta direção tem condições de controlar praticamente o ensino desta outra importante matéria" (LEDDA, 1936, não paginado, tradução nossa ${ }^{27}$ ).

Em 1936, iniciaram as premiações mensais. Elas incentivavam os alunos para o estudo. No relatório de Ledda daquele ano, vê-se que os prêmios eram distribuídos aos estudantes que mais haviam estudado ou melhor realizado os desenhos, ou tinham mantido os cadernos em ordem. Dizia Ledda que "[...] se faz de tudo para que os alunos cresçam perfeitos balillas e bons italianos" (LEDDA, 1936, não paginado, tradução nossa $\left.{ }^{28}\right)$.

\footnotetext{
26 "per educare gli alunni al culto dell'Italia e del Duce".

27 “In questo modo la Direzione è nelle condizioni di controllare praticamente l'insegnamento di quest'altra importante materia".

28 "si fa di tutto perché gli alunni crescano perfetti balilla e buoni italiani”.
} 
Os rituais e as cerimônias foram, então, combinados com os apelos destinados a flanquear as iniciativas em apoio ao regime em diferentes épocas, mas, em particular, durante o período que precedeu e acompanhou a ocupação e a conquista da Etiópia e a consequente formação do império colonial:

Dado o momento excepcional que a Itália está vivenciando, o encerramento do ano letivo aconteceu de maneira simples. Os boletins foram distribuídos durante o canto dos hinos da Pátria e da Revolução. Todos os esforços da Comunidade visam agora angariar fundos e ouro para a resistência nacional contra as sanções injustas de Genebra. Nesta campanha altamente educativa, modesta mas com entusiasmo, os alunos participaram, oferecendo cofrinhos, pequenas quantias, objetos de ouro e prata e outros metais. (LEDDA, 1935b, não paginado, tradução nossa ${ }^{29}$ )

Os eventos da política internacional, centrados no empreendimento colonial etíope, são lidos como eventos que facilitaram o ensino e o trabalho dos professores, despertando um sentimento de orgulho e pertencimento fascista, completamente inéditos de acordo com Ledda, que observou:

É consciencioso acrescentar que a guerra colonial que a Itália luta apesar de tudo facilitou o trabalho dos professores. No entanto, pode-se dizer que enquanto até o ano passado um aluno nosso geralmente não se orgulhava de ser italiano, agora ele grita na praça e questiona com todos, muitas vezes até em casa, onde ele encontra parentes indiferentes ou preocupados de não serem muito italianos [...] Os alunos da terceira, quarta e quinta, são agora perfeitos Balilla, que não têm mais vergonha de cumprimentar seu professor com a saudação romana se eles o encontrarem fora da escola. (LEDDA, 1935b, não paginado, tradução nossa ${ }^{30}$ )

\footnotetext{
29 "Dato il momento eccezionale che attraversa l'Italia, la chiusura dell'anno scolastico ha avuto luogo in maniera semplice. Si sono distribuite le pagelle al canto degli inni della Patria e della Rivoluzione. Tutti gli sforzi della Collettività sono ora rivolti alla raccolta di fondi e dell'oro per la resistenza Nazionale contro le inique sanzioni di Ginevra. A questa campagna, altamente educativa, modestamente, ma con entusiasmo, hanno partecipato gli alunni, offrendo salvadanai, piccole somme, oggettini di oro e d'argento e altri metalli".

30 "È coscienzioso aggiungere che la guerra coloniale che l'Italia combatte a dispetto di tutti ha facilitato l'opera dei maestri. Comunque si può dire che mentre fino all'anno scorso un nostro alunno, generalmente, non si vanta di essere italiano, ora lo grida in piazza e fa questione con tutti, spesso anche in casa, ove trova dei parenti indifferenti o solamente preoccupati di non farsi vedere troppo italiani [...] Gli alunni di terza, quarta e quinta, sono ormai dei Balilla perfetti che non si vergognano più di salutare romanamente il loro maestro se lo incontrano fuori di scuola".
} 
Ledda é um professor que conhece e percebe as mudanças ocorridas no contexto do Rio Grande do Sul em que as tensões nacionalistas estavam crescendo. No entanto, não parece dar muito crédito à possibilidade real de que mudanças radicais possam ser registradas no estado sul-rio-grandense. Em suas anotações, como a de 1936, ele revela a certeza otimista, em alguns momentos quase sarcástica, sobre a possibilidade de continuar o trabalho de fascistização da juventude de origem italiana, uma certeza que, logo em seguida, teria sido negada pelos fatos:

Os regulamentos escolares em estudo em todos os Estados da Confederação são baseados exclusivamente na Constituição do país que não proíbe a instituição de escolas estrangeiras. Várias tentativas de reforma destinadas a impedir o funcionamento de escolas estrangeiras falharam até agora. Acredita-se que muitas décadas passarão antes que uma ideia tão expressa possa triunfar, já que o país é habitado por estrangeiros respeitados e conhecidos e as escolas locais ainda existem somente no papel. Em conclusão, nossas escolas sempre manterão uma educação tipicamente italiana e, portanto, fascista [...] (LEDDA, 1936, não paginado, tradução nossa ${ }^{31}$ )

Embora o contexto fosse mais problemático, determinado pelas medidas que se seguiram à inauguração do Estado Novo de Vargas, as escolas ítalo-brasileiras parecem continuar a poder desempenhar as funções de propaganda e de educação fascista, solicitadas pela direção geral, liderada por Parini. O diretor pedagógico Luigi Ledda, em seus relatórios trimestrais enviados ao ministério, não deixou de garantir o cumprimento dessas diretrizes e de destacar os resultados positivos do ponto de vista da educação fascista e não escondeu seu otimismo sobre os desenvolvimentos futuros: "Os alunos das classes altas falam e escrevem discretamente, amam firmemente sem qualquer respeito humano a Itália fascista [...] O ano letivo de 1938-XVI vai ver nossas melhores escolas, muito melhor. A fé não falta" (LEDDA, 1937b, não paginado, tradução nossa ${ }^{32}$ ).

\footnotetext{
31 "I regolamenti scolastici in studio presso tutti gli Stati della Confederazione si basano esclusivamente sulla Costituzione del paese che non proibisce l'istituzione di scuole straniere. Diversi tentativi di riforma studiati per ostacolare il funzionamento delle scuole straniere sono finora falliti. Si reputo che passeranno molti decenni prima che una tale espressa idea possa trionfare essendo il paese abitato quasi tutto da stranieri rispettati e benvoluti e le scuole locali sono ancora esistenti sulla carta. In conclusione le nostre scuole conserveranno sempre indirizzo educatvo tipicamente italiano e quindi fascista [...]".

32 "Gli alunni delle Classi superiori parlano e scrivono discretamente, amano fermamente e senza alcun rispetto umano l'Italia Fascista [...] L'Anno scolastico 1938-XVI vedrá insomma le nostre scuole migliori, molto migliori. La fede non manca".
} 
Apesar do trabalho constante, o papel dos professores estava sujeito a mudanças no contexto e autoridades consulares. Com a chegada do novo cônsul Santovincenzo, de fato, a parábola descendente do diretor didático cuja presença, até agora, era considerada contraproducente aos interesses da comunidade porto-alegrense, é acelerada. Sua transferência teria sido "benéfica para todos". Embora reconhecendo “boas qualidades” para o professor como “disciplina, disposição, etc.”, sua permanência em Porto Alegre foi contraproducente:

São muitos os motivos que me levam a solicitar essa mudança, mas uma especialmente é decisiva, ou seja, que o trabalho de Ledda no ambiente colonial, dada a sua irrelevância e facilidade em falar, dificulta (para usar uma palavra branda) toda ação consular mesmo em campos que não são puramente educativos. Acrescentarei também que ele adquiriu uma verdadeira antipatia em todos os ambientes, a tal ponto que, se em qualquer questão, Ledda parece ser suficiente para fazer qualquer iniciativa afundar. (SANTOVINCENZO, 1938, não paginado, tradução nossa ${ }^{33}$ )

Diante das novas perspectivas, os "escritos profissionais" do diretor didático são bastante mesquinhos. Nesse caso, neles constam os silêncios que se tornam mais significativos, juntamente com as poucas palavras de despedida que revelam uma veia controversa, quando Ledda registra: "Parto sereno e tranquilo, convencido de que sempre cumpri meu dever" (LEDDA, 1937b, não paginado, tradução nossa ${ }^{34}$ ).

\footnotetext{
33 "Molti sono i motivi che mi spingono a sollecitare questo cambiamento ma uno specialmente è determinante, e cioè che l'opera del Ledda nell'ambiente coloniale, data la sua irriflessività e facilità nel parlare intralcia (per usare una parola blanda) tutta l'azione cosolare anche in campi che non sono puramente scolastici. Aggiungerò inoltre che egli si è acquistata una vera antipatia in tutti gli ambienti al punto che se in qualche questione appare il Ledda basta questo per far naufragare qualsiasi iniziativa".

34 "Parto sereno e tranquillo, convinto di aver fatto sempre il mio dovere".
} 


\section{Referências}

ACTON, Errico. Rapporto del regio Vice Console Acton. Archivio Storico Diplomatico del ministero degli Affari Esteri [agora para diante ASMAE], Fondo Archivio Scuole [agora para diante AS] 1889-1910, busta [agora para diante b.] 339. Maggio 1890.

BARAUSSE, Alberto. Chamas da educação nacional e do sentimento pátrio: as escolas italianas no rio grande do sul da colonização ao final do século 19 (1875-1898). História da Educação, Porto Alegre, v. 21, p. 41 - 85, 2017 [a]. Disponível em:

http://www.scielo.br/scielo.php?pid=S223634592017000100041\&script=sci_abstract\&tlng =pt. Acesso em: 28 out. 2018.

BARAUSSE, Alberto. From the Mediterranean to the Americas. Italian ethnic schools in Rio Grande do Sul between emigration, colonialism and nationalism (1875-1925). SisyphusJournal of Education, Lisboa, v. 4, p. 144 - 172, 2016. Disponível em:

https://revistas.rcaap.pt/sisyphus/article/view/10462. Acesso em: 30 out. 2018.

BARAUSSE, Alberto. Le scuole italiane nel Rio Grande do Sul attraverso le carte consolari tra la fine dell'Impero e I'inizio della Repubblica (1875-1893). In: DE RUGGIERO, Antonio; HEREDIA, Vania. B. M.; BARAUSSE, Alberto. História e narrativas transculturais entre a Europa Mediterrânea e a América Latina. 1 ed. Porto Alegre: EDIPUCRS, 2017b.p. 195-248. V.1

BARAUSSE, Alberto. Nationalism and schooling: between italianity and brazilianity. Dispute in education of Italian gaucho people (RS, 1930-1945). History of Education and Childrens' Literature, Macerata, v. XII, n. 2, p. 443-475, 2017c.

BARAUSSE, Alberto; LUCHESE, Terciane A. Da Itália ao Brasil: processos educativos e formativos, séculos 19 e 20. História da Educação, Porto Alegre, v. 21, p. 33 - 40, 2017. Disponível em: https://seer.ufrgs.br/asphe/article/view/68983. Acesso em: 30 out.2018.

BARAUSSE, Alberto; LUCHESE, Terciane Ângela. Nationalism and schooling: between italianity and braziliity. Dispute in education of Italian gaucho people (RS, 1930-1945). History of Education and Childrens' Literature, Macerata, v. XII, n. 2, p. 443-475, 2017b.

BARAUSSE, Alberto; LUCHESE, Terciane Ângela. Uma história dos (i)migrantes italianos entre o local e o transnacional: entrecruzando documentos e olhares investigativos. In: KARSBURG, Alexander; VENDRAME, Máira Ines (orgs.). Variações da Micro-História no Brasil: temas, abordagens e desafios. 1 ed. São Leopoldo: Oikos, 2019. p. 171- 203.

BARAUSSE, Alberto; LUCHESE, Terciane Ângela.Da Itália ao Brasil: processos educativos e formativos, séculos 19 e 20. História da Educação, Porto Alegre, v.21, p.33 - 40, $2017 a$.

BERTONHA, João Fabio. O fascismo e os imigrantes italianos no Brasil. Porto Alegre: EDIPUCRS, 2001. 
BRICHANTEAU, Edoardo di Compans. Rapporto del regio console Brichanteau. ASMAE, AS, 1889-1910, b. 339, fascicolo [agora para diante f.] Scuole al Brasile fino al 1898. 6 febbraio 1892.

CARLI, Mario. Rapporto annuale del Console generale Mario Carli. ASMAE, Direzione Generale Italiani all'Estero [agora para diante DGIE], AS, Personale docente non più in servizio (1920-1955), b. 305, f. Ledda Luigi. 27 giugno 1933 [b].

CARLI, Mario. Rapporto del console Mario Carli. ASMAE, AS 1929-1935, b. 785, f. Porto Alegre. Maggio 1933 [a].

CERETTA, Antonio, História de São João de Polesine desde o inicio de sua colonização ate o ano de [1936 escrita pelo Professor António Ceretta], s.d. [ma probabilmente del 1936]. Caderno II. Arquivo Histórico Provincial Nossa Senhora Conquistadora, Santa Maria [Ceretta s.d. mas 1936].

CERETTA, Antonio, Historia de Vale Veneto. Desde o ano de 1877 até o año de 1886 Traduzida e remodelata em 1941 (?) da escrita em 1894. Em Arquivo Histórico Provincial Nossa Senhora Conquistadora, Santa Maria, [1941].

CERETTA, Antônio. História do São João do Polêsine: desde o início de sua colonização até o ano de 1936. POMMER, Roselene; KEMMERICH, Ricardo (org.). São João do Polêsine: Prefeitura Municipal de São João do Polêsine; Santa Maria: Universidade Federal de Santa Maria, Colégio Técnico Industrial de Santa Maria, 2015.

CERETTA, Antonio. Relazione del maestro Antonio Ceretta. ASMAE, AS, 1889-1910, b. 339, f. Scuole al Brasile fino al 1898, sf. Silveira Martins. 24 dicembre 1890.

CORTE, Pasquale. Relazione [del Console Generale d'Italia Pasquale Corte] sulle scuole italiane esistenti nella provincia di Rio Grande del Sud. ASMAE, AS Scuole 1868-1888, b. 218 P-S. 15 luglio 1884.

DE RUGGIERO, Antonio. A voz do imigrante: memória e oralidade nos estudos históricos das migrações. Porto Alegre: Editora Fi, 2018.

DE RUGGIERO, Antonio; HEREDIA, Vania. B. M.; BARAUSSE, Alberto. História e narrativas transculturais entre a Europa Mediterrânea e a América Latina. Porto Alegre: EDIPUCRS, 2017. p. 320.v.1.

FLORIANI, Giorgio. Scuole italiane all'estero: cento anni di storia. Roma: Armando Editore, 1974.

FRANZINA, Emilio. L'immigrazione veneta in Rio Grande do Sul nelle memorie di Giulio Lorenzoni. In: FRANZINA, Emilio. La terra ritrovata: storiografia e memoria della prima immigrazione italiana in Brasile. Genova: Stefano Termanini Editore, 2014. p. 177-230. 
IL 23 MARZO, alla sede della Dante Alighieri, si sono inaugurate ufficialmente le quattro scuole italiane di Porto Alegre. Nuova Italia, Porto Alegre, ano I, 29 marzo 1933.

IL REGIO CONSOLE Generale d'Italia Comm. Guglielmo Barbarisi lascia Porto Alegre. La Voce d'Italia, Porto Alegre, ano III, 30 aprile 1937.

L'andamento della scuola al primo semestre di Antonio Ceretta s.d. in ASMAE, AS, 18891910, b. 339, f. Scuole al Brasile fino al 1898, sf. Silveira Martins. s.d.

LA NUOVA organizzazione. Nuova Italia, Porto Alegre, Ano I, 25 marzo 1933.

LEDDA, Luigi. Relazione di Luigi Ledda. ASMAE, AS 1929-1935, b. 785, f. Porto Alegre 193435. 30 settembre 1932 [a].

LEDDA, Luigi. Relazione finale dell'insegnante Luigi Ledda sull'anno scolastico 1932. ASMAE, AS 1929-1935, b. 785, f. Porto Alegre 1934-35, sf. Scuole italiane. 16 dicembre 1932[b].

LEDDA, Luigi. Relazione del direttore didattico L. Ledda relativa al trimestre settembreottobre-novembre 1935. ASMAE, AS 1929-1936, b. 63, f. Porto Alegre 1934-35. 31 dicembre 1935[b].

LEDDA, Luigi. Relazione trimestrale del direttore didattico Luigi Ledda aprile maggio giugno 1936 allegata alla nota di accompagnamento del R. Console Barbarisi del 2 luglio 1936. ASMAE, AS 1936-1945, b. 63, f. Porto Alegre. 15 giugno 1936.

LEDDA, Luigi. Relazione trimestrale del direttore didattico Luigi Ledda, ASMAE, AS 19361945, b. 63, f. Porto Alegre. 17 giugno 1937[a].

LEDDA, Luigi. Relazione trimestrale del direttore didattico Luigi Ledda. ASMAE, AS 19361945, b. 63, f. Porto Alegre. 12 settembre 1937[b].

LEDDA, Luigi. Relazione trimestrale del direttore didattico Luigi Ledda. ASMAE, AS 19361945 , b. 63.23 settembre 1937 [c].

LEDDA, Luigi. Stato di servizio di Ledda Luigi. ASMAE, DGIE AS, Personale docente non più in servizio (1920-1955), b. 305, f. Ledda Luigi. s.d.

LE SCUOLE italo brasiliane in Porto Alegre. Origine, organizzazione, attività. La Voce d'Italia, Porto Alegre, ano II, 17 settembre 1936.

LE NOSTRE scuole. Nuova Italia, Porto Alegre, Ano I, 27 marzo 1933.

LORENZONI, Giulio. Memorie di un emigrante italiano: (a cura di) Emilio Franzina. Vicenza: Istituto per le ricerche di storia sociale e religiosa; Roma: Viella, 2008.

LORENZONI, Júlio. Memórias de um imigrante italiano. Porto Alegre: Sulina, 1975. 
Nuovi orari e Programmi per le scuole italiane all'estero. Ordinanza del 1 ottobre 1924. In: ORIANI, Alfredo. La legislazione fascista sulle scuole italiane all'estero. Torino: Paravia G.B. e C., 1926.

PARINI, Piero. Gli italiani nel mondo. Milano: A. Mondadori, 1935.

PARINI, Piero. Nota di Piero Parini. ASMAE, AS 1929-1935, b. 785, sf. Brasile 1934-35, cat. III-1. 16 febbraio 1935

PARINI, Piero. Programmi didattici per le scuole elementari: Roma 18 ottobre 1930: anno VIII. In: Raccolta delle circolari e istruzioni ministeriali organizado por Angelo Toscani, vol. VIII dal 1 gennaio 1930 al 31 dicembre 1933. Roma, Tipografia del Ministero degli Affari Esteri, 1934- XII. p. 103-111.

PIO DI SAVOIA, Gherardo. Scuole italiane nel Rio Grande do Sul. Allegato alla relazione del regio console Gherardo Pio Di Savoia del 18 febbraio 1894. ASMAE, AS, 1889-1910, b. 339, f. Scuole al Brasile fino al 1898, sf. Carte sciolte. 18 febbraio 1894.

Presidente del Consiglio scolastico provinciale di Vicenza. Archivio Centrale dello Stato [Italiano], Fondo Ministero Pubblica Istruzione, Direzione Generale Istruzione Primaria e Normale 1860-1896, b. 115 bis, f. 1876.16 maggio 1876.

RECH, Gelson L. Escolas étnicas em Porto Alegre/RS (1877-1938): a formação de uma rede escolar e o fascismo. 2015. 449 f. Tese (Doutorado em Educação) - Programa de Pósgraduação em Educação, Universidade Federal de Pelotas, Pelotas, 2015.

RIGHI, José Vicente; BISOGNIN, Edir Lucia; TORRI, Valmor. Imigrantes da Grande Colônia nucleo Norte-Nucleo Soturno. In: RIGHI, José Vicente; BISOGNIN, Edir Lucia; TORRI, Valmor. Povoadores da Quarta Colônia. Porto Alegre: EST, 2001.

SALVETTI, Patrizia. Le scuole italiane all'estero. In: BEVILACQUA, Piero; DE CLEMENTI, Andreina, FRANZINA, Emilio (orgs.). Storia dell'emigrazione italiana: arrivi. Roma: Donzellli, 2002. p. 535-549.

SANTOVINCENZO, Magno. Nota per l'ispettore G. Gabrielli: allegata al Telespresso del Console Santovincenzo Magno al Capo Ufficio Scuole Carosi del 26 gennaio 1938, in ASMAE, DGIE AS, Personale docente non più in servizio (1920-1955), b. 305, f. Ledda Luigi. 4 gennaio 1938.

TONI, Piero. Nota della Legazione d'Italia firmata da Piero Toni. ASMAE, DGIE AS, Personale docente non più in servizio (1920-1955), b. 305, f. Ledda Luigi. 28 agosto 1939 [a].

TONI, Piero. Telegramma della R. Legazione di Assuncion firmato da Piero Toni. ASMAE, DGIE AS, Personale docente non più in servizio (1920-1955), b. 305, f. Ledda Luigi. 30 agosto 1939[b]. 
VENDRAME, Maíra Ines. Lá éramos servos, aqui somos senhores: a organização dos imigrantes italianos na ex-colônia Silveira Martins (1877-1914). Santa Maria: Ed. da UFSM, 2007.

VENDRAME, Maíra Ines. Memórias de imigrantes: fontes para o estudo da imigração italiana, In: DE RUGGIERO Antonio. A voz do imigrante: memória e oralidade nos estudos históricos das migrações. Porto Alegre: Editora Fi, 2018. p. 63-88.

VIÑAO FRAGO, Antonio. La memoria escolar. Restos y huellas, recuerdos y holvidos. Annali di Storia dell'educazione e delle istituzioni scolastiche, 12, p. 19-33, 2005.

ZANINI, Catarina Maria Chitolina. Italianidade no Brasil meridional: a construção da identidade étnica na região de Santa Maria - RS. Santa Maria: Ed. da UFSM, 2006.

Universidade do Estado de Santa Catarina - UDESC

Programa de Pós-Graduação em Educação - PPGE

Revista Linhas

Volume 20 - Número 44 - Ano 2019 revistalinhas@gmail.com 